\title{
Erratum to: Evaluation of needle trap micro-extraction and automatic alveolar sampling for point-of-care breath analysis
}

\author{
Phillip Trefz • Lisa Rösner • Dietmar Hein • \\ Jochen K. Schubert • Wolfram Miekisch
}

Received: 16 April 2013 /Accepted: 16 April 2013 /Published online: 27 April 2013

(C) Springer-Verlag Berlin Heidelberg 2013

\section{Erratum to: Analytical and Bioanalytical Chemistry}

DOI 10.1007/s00216-013-6781-9

The authors should like to call your attention to the fact that unfortunately the reference in the following sentence in the discussion was incorrect:

"Alonso et al. obtained good reproducibility for analysis of a mixture of ten aromatic compounds with sampling flow rates of $15 \mathrm{~mL} / \mathrm{min}$ using NTDs packed with Tenax and with flow rates of $5 \mathrm{~mL} / \mathrm{min}$ using Carbopack $\mathrm{X}$ as sorbent [9]".

The citation [9] here should be replaced by the following reference:

Alonso, M., et al., Needle microextraction trap for on-site analysis of airborne volatile compounds at ultra-trace levels in gaseous samples. Journal of Separation Science, 2011. 34(19): p. 2705-2711.

The online version of the original article can be found at http://dx.doi.org/ 10.1007/s00216-013-6781-9.

P. Trefz $\cdot$ J. K. Schubert $\cdot$ W. Miekisch $(\bowtie)$

Department of Anaesthesia and Intensive Care,

University of Rostock, Schillingallee 35,

18057 Rostock, Germany

e-mail: wolfram.miekisch@medizin.uni-rostock.de

L. Rösner · D. Hein

PAS Technology Deutschland GmbH, Richard-Wagner-Strasse 10,

99441 Magdala, Germany 